\title{
Patient Satisfaction Towards Dentist-Patient Interaction Among Patients Attending Outpatient Dental Clinic Hospital Universiti Sains Malaysia
}

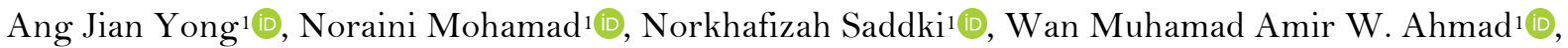 \\ Mohammad Khursheed Alam²(1)
}

${ }^{1}$ School of Dental Sciences, Health Campus, Universiti Sains Malaysia, Kelantan, Malaysia. ${ }^{2}$ College of Dentistry, Jouf University, Sakaka, Kingdom of Saudi Arabia.

Correspondence: Noraini Mohamad, MD, MMed (Family Medicine), School of Dental Sciences, Health Campus, Universiti Sains Malaysia, 16150 Kubang Kerian, Kelantan, Malaysia. E-mail: mnoraini@usm.my

Academic Editor: Alessandro Leite Cavalcanti

Received: 07 June 2020 / Review: 24 August 2020 / Accepted: 09 October 2020

\begin{abstract}
How to cite: Yong AJ, Mohamad N, Saddki N, Ahmad WMAW, Alam MK. Patient satisfaction towards dentist-patient interaction among patients attending outpatient dental clinic hospital Universiti Sains Malaysia. Pesqui Bras Odontopediatria Clín Integr. 2021; $21: e 0123$. https://doi.org/10.1590/pboci.2021.041
\end{abstract}

\begin{abstract}
Objective: To determine the satisfaction with the dentist-patient interaction and factors associated with patient satisfaction among patients attending the outpatient dental clinic Hospital Universiti Sains Malaysia (HUSM). Material and Methods: This cross-sectional study involved 229 patients who attended outpatient dental clinic Hospital USM that located in the East Coast region of Malaysia. A selfadministered Skala Kepuasan Interaksi Perubatan - 11 (SKIP-11) questionnaire was used to assess the satisfaction towards dentist-patient interaction. Systematic random sampling was applied in this study. The data were analyzed using simple logistic regression analysis to determine the factors associated with patient satisfaction with dentist-patient interaction. Results: The mean age of patients was $32.6 \pm 13.9$ years, $71.6 \%$ of them study up to tertiary level, $31.5 \%$ came to for dental check up and $23.6 \%$ of them had tooth decay. More than half $(64.6 \%)$ of the patients were satisfactory with dentist-patient interaction. The satisfaction percentage in the distress relief domain was $60.7 \%, 56.8 \%$ in the rapport domain, and $53.7 \%$ in the interaction outcome domain. Satisfaction with dentist-patient interaction was significantly associated with the dentists' characteristics such as age $(\mathrm{OR}=0.583,95 \% \mathrm{CI} 0.44-0.76, \mathrm{p}=0.001)$, gender $(\mathrm{OR}=0.386,95 \%$ CI $0.22-0.69, p=0.001)$ and years of service $(\mathrm{OR}=0.294,95 \%$ CI $0.15-0.57, \mathrm{p}=0.001)$. Conclusion: The result showed that slightly more than half of the patients who attended the outpatient dental clinic HUSM were satisfied with the dentist-patient interaction, which was found to be influenced by the characteristics of the dentists. Efforts to improve patient-dentist interaction are recommended to ensure delivery of good quality oral health care.
\end{abstract}

Keywords: Attitude to Health; Patient Satisfaction; Professional-Patient Relations. 


\section{Introduction}

Patients' satisfaction is a match of expectations with their experiences during a treatment process [1]. Patients' satisfaction has become an important indicator and is commonly used to measure the quality of health care [2]. Patients' satisfaction has a direct correlation with clinical outcomes, improved patient retention, patient loyalty, reduced risk of medical malpractice claims, and increased personal and professional satisfaction [Q]. It is a very effective indicator to measure the success of doctors and hospitals [Q].

In the dental sector, patients' satisfaction is an equally important indicator as it can influence the pattern of service utilization [3]. Fulfillment of patient demands, positive assurance, good responses to patient, resolve confusions and doubts of the patient provides better satisfaction and result in a future return of the patients to receive subsequent good quality of treatment [4].

Studies in Saudi Arabia and India found that the main factors related to patient satisfaction includes patient-dentist interaction, technical competency, administrative efficiency, and clinic setup environment [4,5]. Patients in Saudia Arabia were satisfied with all factors listed above [5]. However, patients in India expressed high satisfaction with the patient-dentist interaction $(88.2 \%)$, least with technical competency (50\%), and moderate with administrative and clinic setup (66\%) [4].

Several factors are associated with patient satisfaction towards dentist, which included patients' past experiences while getting treatment from the dentist [6]. A study in Norway found that satisfaction with dental care was associated with positive beliefs of the dentist, low dental anxiety, perception of having a dentist to go to, last treatment session not painful/unpleasant, and treatment received from male dentist [6]. Very dissatisfied patients were associated with low general well-being, previous experiences of pain, dislike of the dentist and last dental treatment session was reported to be very painful or unpleasant [6]. A study in Kelantan, Malaysia in 2011 found that responsiveness, assurance, and empathy showed by dental health care providers were among the factors that needed to be considered for patient satisfaction towards the service given to them [7]. They also found that there was no significant association between patient satisfaction and their age, gender, marital status, or personal income [7]. While a review article on patient satisfaction in 1997 indicated that satisfaction with health care providers depend on the patients' social class, marital status, gender, and in particular the age of the patient [8].

Effective doctor-patient communication is central to a therapeutic doctor-patient relationship, which is the art and heart of medicine [9]. Most complaints from dissatisfied patients were due to the breakdown in the doctor-patient relationship [9]. However, many doctors or dentists tend to overestimate their ability to communicate with their patients [9]. Therefore, this study was conducted to measure the patients' satisfaction with dentist patient interaction in an outpatient dental clinic Hospital Universiti Sains Malaysia by using psychometric properties of the ‘Skala Kepuasan Interaksi Perubatan-11’ (SKIP-11) [10].

\section{Material and Methods}

\section{Study Design and Sampling}

This study is a cross-sectional study that was conducted between June to July 2017 in the outpatient dental clinic Hospital USM based on selected weeks. The estimated population was 2240 patients who attended outpatient dental clinic Hospital USM during the study period. A systematic random sampling with a ratio of 1:4 was used to select respondents for an interview. Patients who were aged 18 and above and able to read and write in Malay language were included in the study. Those who were illiterate and suffering from a psychiatric illness were excluded. The sample size was calculated using the single proportion formula with a $95 \%$ 
confidence interval (CI). The expected proportion of respondents who were satisfied with the doctor-patient interaction was estimated at $76 \%$ as reported by Norhayati et al. [11] among patient in Malaysia. The sample sizes were calculated for various levels of precision and a sample size of 192 was chosen with a precision of 0.06 while taking into consideration available resources. Taking into account non-response rate of $20 \%$, a sample size of 230 was decided for this study. The sample size was then adjusted according to standard criteria for prevalence, inflated by design effect (DE) which was equal to 1 .

\section{Questionnaire}

A self-administered questionnaire was used to collect the variables of interest in this study. The questionnaire has 3 parts. The first part was on socio-demographic characteristics of the respondents including age, sex, ethnic group, education level, occupation, income, marital status, chronic illness (having a chronic illness or not), dental diagnosis and type of patient (new or follow up patient), and type of treatment received from a dentist. The second part of the questionnaire was on patients' satisfaction by using 'Skala Kepuasan Interaksi Perubatan-11' questionnaire. SKIP-11 questionnaire was originated from the Medical Interview Satisfaction Scale-2 1 (MISS-2 1). MISS-2 1 was published in 2002 and it consists of twenty-one items with four domains of doctor-patient interaction, which were distress relief (six items), rapport (eight items), communication comfort (three items), and compliance intent (four items) [12]. SKIP-11 questionnaire consists of three domains which were: (i) information provided by the doctor (distress relief; four items), (ii) patient's confidence in doctor (rapport; four items) and (iii) doctor-patient interaction outcome (interaction outcome; three items). The translated and validated Malay version of SKIP-11 consists of 11 items and used in this study with permission from the author [10]. The item analysis was satisfactory for selected items as the overall Cronbach's alpha value was 0.669 [10]. Classification into satisfied and dissatisfied categories were based on score of the overall items and score of the items for each subscale; score $>44$ for overall items and score $>16$ for distress, $>16$ for rapport and $>12$ for interaction outcome subscales are considered as satisfied [11]. For SKIP-1 1 questionnaire items, 5 Likert scale (strongly agree $=5$, agree $=4$, unsure $=3$, disagree $=2$ and strongly disagree $=1$ ) were applied. For positive wording questions which were questions number 1 to 9 , scores of ' 5 ' ' 4 ', '3', '2' and ' 1 ' for 'strongly agree', 'agree', 'unsure', 'disagree' and 'strongly disagree' were used, respectively. This scoring was reversed for negative items questions which were questions number 10 and 11 . The third part of the questionnaire enquires particulars of the dentist attending the patient on that day, which were their age, sex, and total year of service.

\section{Data Collection Procedure}

All of the respondents were briefed on this study by the researcher during their dental visits. Written informed consent was obtained from those who agreed to participate. The self-administered questionnaire was given to the respondents after they received their dental treatment. The questionnaires were collected on the same day, and the answers were checked for their completeness. Then, the questionnaire on dentist particulars including their age, sex, total year of service was given to the dentist after they finish treating the patient.

\section{Statistical Analysis}

Data entry and analysis were done using IBM SPSS Statistics for Windows (version 24.0, IBM Corp., Armonk, NY, USA). Data checking and cleaning were done before the data analysis. Descriptive statistics were used to describe the sociodemographic characteristics of the respondents and to determine the proportion of 
patients who were satisfied with their interaction with the dentist in the outpatient clinic, HUSM. Numerical data were presented as a mean and standard deviation (SD), and categorical data were presented as frequency and percentage.

Simple logistic regression analysis was used to determine the factors associated with patient satisfaction with dentist-patient interaction among patients attending the outpatient dental clinic in HUSM. The independent variables included socio-demographic characteristics of the respondents, respondents' experience, socio-demographic characteristics of the dentists and dentist total year of service. The dependent variable was the total score of SKIP-11. A score of more than 44 implies that the dentist-patient interaction was satisfactory and a score lower than 44 implies otherwise. The significant level was set at p-value $<0.05$. Following simple logistic regression analysis, variables with p-value less than 0.25 were included in the subsequent multivariable analysis.

All possible associations were checked through the Spearman correlation matrix, which is given in Table 1. It was found that all the selected independent variables have a significant association with each other. Therefore, the multiple logistic regression analyses cannot be performed with these predictor variables, because the multicollinearity effect will affect the model fit. In certain cases, the standard errors will inflate and makes it difficult to gauge the effect of independent variables on dependent variables.

Table 1. Spearman correlation among all the selected variables.

\begin{tabular}{|c|c|c|c|c|c|}
\hline Variables & & 1 & 2 & 3 & 4 \\
\hline 1. Satisfying Status & $\begin{array}{c}\text { Correlation } \\
\text { p-value }\end{array}$ & 1.000 & & & \\
\hline 2. Age of Dental Officer & $\begin{array}{c}\text { Correlation } \\
\text { p-value }\end{array}$ & $\begin{array}{c}-0.255^{* *} \\
0.000\end{array}$ & $\begin{array}{c}1.000 \\
.\end{array}$ & & \\
\hline 3. Sex & $\begin{array}{c}\text { Correlation } \\
\text { p-value }\end{array}$ & $\begin{array}{c}-0.215^{* *} \\
0.001\end{array}$ & $\begin{array}{c}0.744^{* *} \\
0.000\end{array}$ & 1.000 & \\
\hline 4. Dental Officer Service & $\begin{array}{c}\text { Correlation } \\
\text { p-value }\end{array}$ & $\begin{array}{c}-0.236^{* *} \\
0.000\end{array}$ & $\begin{array}{c}0.888^{* *} \\
0.000\end{array}$ & $\begin{array}{c}0.501^{* *} \\
0.000\end{array}$ & $\begin{array}{c}1.000 \\
.\end{array}$ \\
\hline
\end{tabular}

***arrelation is significant at the 0.01 level (2-tailed).

Ethical Approval

This study was approved by the Human Research and Ethics Committee, Universiti Sains Malaysia (USM) on 19th June 2017 (USM/JEPeM/17040205).

\section{Results}

A total of 230 patients were invited to participate in this study and 229 responded, resulting in $99.5 \%$ response rate. The socio-demographic profile of the respondents are shown in Table 2 . Their ages ranged from 18 to 75 years old with a mean age of 32.6 years $(\mathrm{SD}=13.9)$. Slightly more than half $(64.2 \%)$ were female and majority (93.9\%) of the respondents were Malay. Approximately two third of the respondents had received tertiary education $(71.6 \%)$ and more than half were unemployed $(57.6 \%)$. Majority $(83.4 \%)$ of the respondents income were below RM3000 and about half (52.4\%) of them still single. About quarter (24\%) of the respondents had medical problems such as hypertension, diabetes mellitus or hypercholesterolemia. One-third of the respondents came for a dental check-up (31.5\%), had tooth decay or tooth sensitivity (23.6) or toothache (20.5\%). More than two-thirds (72.5\%) of the respondents had multiple visits to the dental clinic.

The dentists characteristics are shown in Table 3. The age of the dentist ranged from 25 to 28 years old. Slightly more than half (62.5\%) were female dentist. $37.5 \%$ of them had working experienced for less than two years and more than three years. 
Table 2. Patients characteristics.

\begin{tabular}{|c|c|}
\hline Variables & $\mathbf{N}(\%)$ \\
\hline \multicolumn{2}{|l|}{ Age } \\
\hline $18-25$ Years Old & $105(45.9)$ \\
\hline $26-40$ Years Old & $64(27.9)$ \\
\hline$>40$ Years Old & $60(26.2)$ \\
\hline \multicolumn{2}{|l|}{ Sex } \\
\hline Male & $82(35.8)$ \\
\hline Female & $147(64.2)$ \\
\hline \multicolumn{2}{|l|}{ Ethic Group } \\
\hline Malay & $215(93.9)$ \\
\hline Others & $14(6.1)$ \\
\hline \multicolumn{2}{|l|}{ Educational Level } \\
\hline Primary/Secondary School & $65(28.4)$ \\
\hline Tertiary Level & $164(71.6)$ \\
\hline \multicolumn{2}{|l|}{ Occupation Status } \\
\hline Employed & $97(42.4)$ \\
\hline Unemployed & $132(57.6)$ \\
\hline \multicolumn{2}{|l|}{ Individual Monthly Income (Rm) } \\
\hline $\mathrm{Rm}<3000$ & $191(83.4)$ \\
\hline $\mathrm{Rm}>3001$ & $38(16.6)$ \\
\hline \multicolumn{2}{|l|}{ Marital Status } \\
\hline Married & $109(47.6)$ \\
\hline Single & $120(52.4)$ \\
\hline \multicolumn{2}{|l|}{ Having Chronic Illness } \\
\hline Yes & $55(24)$ \\
\hline No & $174(76)$ \\
\hline \multicolumn{2}{|l|}{ Dental Diagnosis } \\
\hline Toothache & $47(20.5)$ \\
\hline Tooth Decay/Sensitivity & $54(23.6)$ \\
\hline Restoration Fracture/Dislodge & $34(14.8)$ \\
\hline Bleeding Gum/Tooth Mobile & $16(7.0)$ \\
\hline Prosthetic & $6(2.6)$ \\
\hline Dental Checkup/Follow-Up & $72(31.5)$ \\
\hline \multicolumn{2}{|l|}{ Type Of Patient } \\
\hline New Patient & $63(27.5)$ \\
\hline Old Patient & $166(72.5)$ \\
\hline \multicolumn{2}{|l|}{ Type Of Dental Treatment Received } \\
\hline Checkup & $59(25.8)$ \\
\hline Conservative & $84(36.7)$ \\
\hline Periodontics & $46(20.1)$ \\
\hline Prosthodontics & $6(2.6)$ \\
\hline Oral Maxilofacial Surgery & $34(14.8)$ \\
\hline
\end{tabular}

Table 3. Dentists characteristics $(n=8)$.

\begin{tabular}{ll}
\hline \multicolumn{1}{c}{ Variables } & $\mathbf{N}(\mathbf{\%})$ \\
\hline Age 25 Years Old & $1(12.5)$ \\
26 Years Old & $3(37.5)$ \\
27 Years Old & $2(25.0)$ \\
28 Years Old & $2(25.0)$ \\
Sex & \\
Male & $3(37.5)$ \\
Female & $5(62.5)$ \\
Total Service Year & $3(37.5)$ \\
Less Than 2 Years & $2(25.0)$ \\
2 - 3 Years & $3(37.5)$ \\
More Than 3 Years &
\end{tabular}


Subscales and total scales of patient satisfaction using SKIP-11 questionnaire are shown in Table 4. More than half of the patients $(64.6 \%)$ were satisfied with the overall dentist-patient interaction. Specifically, $60.7 \%$ of patients were satisfied with the distress relief domain, $56.8 \%$ with the rapport domain and $53.7 \%$ with the interaction outcome domain.

Table 4. Subscales and total scales of patient satisfaction as measured with SKIP-11.

\begin{tabular}{lccccc}
\multicolumn{1}{c}{ Sub Scale } & Score & Mean & $\left(\mathbf{S D}^{\mathbf{a}}\right)$ & $\mathbf{N}$ & $\mathbf{\%}$ \\
\hline Distress Relief & $>16$ & 17.87 & 2.07 & 139 & 60.7 \\
Rapport/ Confidence & $>16$ & 17.68 & 2.34 & 130 & 56.8 \\
Interaction Outcome & $>12$ & 13.20 & 1.72 & 123 & 53.7 \\
SKIP-11 & $>44$ & 48.76 & 5.68 & 148 & 64.6 \\
\hline
\end{tabular}

Factors associated with patient satisfaction with dentist interaction by simple logistic regression analysis are shown in Table 5. Patient satisfaction with dentist-patient interaction was significantly associated with dentists' characteristics such as age, gender and years of service. The results can be interpreted as follows: 1) For every one year increase in dentist's age, there will be $42 \%$ lesser odds of satisfaction with dentist-patient interaction (OR 0.583, 95\%CI 0.44,0.76, p=0.001). 2) Being a female dentist, there will be $62 \%$ lesser odds of patient satisfaction with dentist-patient interaction than male dentist (OR 0.386, 95\% CI 0.22,0.69, p=0.001). 3) Dentist who have been service for more than three years have $71 \%$ lesser odds of patient satisfaction with dentist-patient interaction than dentist who service less than 2 years (OR 0.294, 95\% CI 0.15,0.57, p=0.001).

Table 5. Factors associated with patient satisfaction with dentist-patient interaction by simple logistic regression analysis.

\begin{tabular}{|c|c|c|c|}
\hline Variables & Crude OR (95\% CI) & Wald Stat (df) & p-value \\
\hline \multicolumn{4}{|l|}{ Respondents' Age } \\
\hline $18-25$ & 1 & & \\
\hline $26-40$ & $1.34(0.69-2.61)$ & $0.724(1)$ & 0.395 \\
\hline$>40$ & $1.002(0.52-1.91)$ & $0.000(1)$ & 0.995 \\
\hline \multicolumn{4}{|l|}{ Respondents' Sex } \\
\hline Male & 1 & & \\
\hline Female & $1.00(0.57-1.76)$ & $0.000(1)$ & 0.999 \\
\hline \multicolumn{4}{|l|}{ Respondents' Ethnic Group } \\
\hline Others & 1 & & \\
\hline Malay & $1.90(0.64-5.64)$ & $1.357(1)$ & 0.244 \\
\hline \multicolumn{4}{|l|}{ Respondents' Educational Level } \\
\hline Primary/Secondary School & 1 & & \\
\hline Tertiary Educational Level & $1.205(0.66-2.18)$ & $0.379(1)$ & 0.538 \\
\hline \multicolumn{4}{|l|}{ Respondents' Occupational Status } \\
\hline Working & 1 & & \\
\hline Not Working & $1.055(0.61-1.82)$ & $0.037(1)$ & 0.847 \\
\hline \multicolumn{4}{|l|}{ Respondents' Income (RM) } \\
\hline$\leq 3000$ & 1 & & \\
\hline$>3001$ & $1.22(0.58-2.58)$ & $0.286(1)$ & 0.593 \\
\hline \multicolumn{4}{|l|}{ Respondents' Marital Status } \\
\hline Single & 1 & & \\
\hline Married & $1.127(0.65-1.94)$ & $0.185(1)$ & 0.667 \\
\hline \multicolumn{4}{|l|}{ Type of Patient } \\
\hline Old Patient & 1 & & \\
\hline New Patient & $1.25(0.674-2.31)$ & $0.499(1)$ & 0.480 \\
\hline Dentists' Age & $0.583(0.44-0.76)$ & $15.01(1)$ & 0.001 \\
\hline \multicolumn{4}{|l|}{ Dentists' Sex } \\
\hline Male & 1 & & \\
\hline Female & $0.386(0.22-0.69)$ & $10.328(1)$ & 0.001 \\
\hline
\end{tabular}




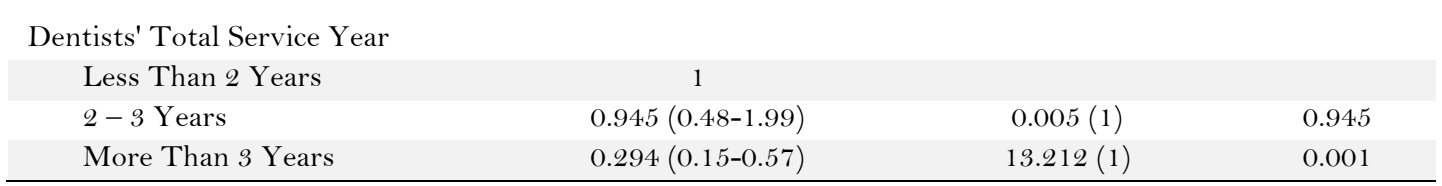

Crude OR = Crude Odds Ratio; 95\% CI= 95\% Confidence Interval; $\mathrm{df}=$ degrees of freedom.

\section{Discussion}

Patient satisfaction is intricately linked to patient outcomes, therefore it is important and requires attention from all health care providers. Patients who are more satisfied are more likely to adhere to treatment plans and maintain their relationships with their healthcare providers [9].

In this study, SKIP-11 questionnaire was used to assess the patients' satisfaction towards dentistpatient interaction. The results shows, more than half (64.6\%) of the patients who attended outpatient dental clinic Hospital USM were satisfied with the overall dentist-patient interaction. The number however is lower compared to other studies in Saudi Arabia (79.5\%) [5] and United Kingdom (89\%) [13]. A comparable finding was reported in a study done by Othman and Razak [14] where they found $62 \%$ of respondents were satisfied with the services provided. Nonetheless, the findings reported by Rohit and Rafeek (34.1\%) [15] and Gurdal et al. [16] (38.6\%) were much lower. With regards to method of assessment for patients' satisfaction, the study in Saudi Arabia used 9 items questionnaire to assess patient-dentist interaction and the items content was not similar to the SKIP-11 items [5] while, Othman and Razak [14] used a validated 10 items questionnaire to assess satisfaction on patient-personnel interaction, which reflects the dental personnel's personality or attitude towards the patient.

Results in the three domains of the SKIP-11 i.e. distress relief, rapport/confidence, and interaction outcome domains showed that $60.7 \%, 56.8 \%$, and $53.7 \%$ of patients were satisfied in the respective domains. Our finding was lower as compared to a study done by Norhayati et al. [11] where they found $85.3 \%$ of patients were satisfied with distress relief domain, $91.2 \%$ were satisfied with rapport/confidence domain and $67.6 \%$ were satisfied with the interaction outcome domain. A study done by Norhayati et al. [11] used SKIP11 questionnaire to assess patient satisfaction with doctor-patient interaction over six months after following prevention counselling and its associations with modifiable cardiovascular risk factors. Clearly, there is room for improvement in these areas. This means that, there were still needs an improvement in term of overall patient-dentist interaction especially on interaction outcome domain and rapport/confidence domain. Interaction outcome domain assessed the patients' behaviour whether the patient able to follow the doctor's advice [10]. Our result indicates that, the patients' felt uneasy or unsure about following the advice given by the dentist. Unfavourable findings in this domain could be due to patients' unwillingness to change their behaviour and adhere to the advice [11]. The rapport/confidence domain is a very important component in maintaining good interaction between patient and dentist as study found that the most encouraging factors in utilization of dental services was the availability of friendly staff [17]. For a dentist to have a good rapport, they need to have a good soft skills and able to communicate with their patients. This is because, soft skills may increase confidence, professionalism, coordination, friendliness, and optimism in an individual to greater extent [18]. Apart from that, patients' main concern in communication with their dentist was the courtesy of the dentist, followed by information interaction, moral support, explaining the procedure and understanding of the patient's feelings. These were the factors that contributed positively to good communication and satisfaction [19]. 
This study found the patients' satisfaction with dentist interaction was significantly associated dentists' age, dentists' gender and dentists' total year of service. Specifically, patients were more satisfied with older dentists, male dentists and dentists who have been in service for less than 2 years. Dentists age may influence patients' satisfaction since older professionals have demonstrated to have better interpersonal skills, were more experienced compared to younger professionals [20,21]. In contrast, in another study, it was reported that patients preferred younger dentists who are more exposed to advances in dental surgery and they are trained in such techniques [22]. The gender of the dentist also plays a significant part in patients' satisfaction. Patients usually tends to prefer same sex dentist because it will reduced shame and fear of physical contact during the examination [20,22]. Some of the patients slightly prefer female dentists as they were perceived as more caring, possesses empathy-related traits such as taking time to discuss ailments with patients and showed effort to make patients more relaxed compared to their male peers [20,21,23]. There were no significant associations observed between patients' satisfaction towards dentist interaction and sociodemographic variables of the patients such age, gender, marital status, educational level, working status and monthly income. Similar findings were observed in a study done in Tukey [16], Trinidad [15] and Saudi Arabia [24]. Sociodemographic factor of the patients does not affect the patients' satisfaction towards dentist interaction could be due to the attitude of the patients in the East Coast region of Malaysia.

There are a few limitations regarding the study paradigm. Patients's satisfaction with dentist-patient interaction may have been affected by other disciplines such as technical competency, administrative efficiency, and environment of the clinic setup [5]. This study only focuses on the interation between the patients and dentists. In addition, the study sample was performed in an outpatient dental clinic at a university hospital and it does not represent all primary healthcare dental clinics.

\section{Conclusion}

In conclusion, $64.6 \%$ of patients who attended Hospital USM outpatient dental clinic were satisfied with their dentist-patient interaction. It was significantly influenced by characteristics of dentists such as age, sex and total year of service. Efforts to improve patient-dentist interaction are recommended to ensure delivery of good quality oral health care. The result of this study can be used by policymakers as a reference to formulate a suitable approach in increasing the level of satisfaction towards dentist interaction in dental clinic. In addition, it will help to improve the quality of oral care services offerred to the patients.

\section{Authors' Contributions}

\begin{tabular}{|c|c|c|}
\hline AJY & (D) https://orcid.org/0000-0002-1358-9083 & $\begin{array}{l}\text { Conceptualization, Methodology, Investigation, Formal Analysis, Writing - Original Draft } \\
\text { Preparation and Writing - Review and Editing. }\end{array}$ \\
\hline NM & https://orcid.org/0000-0002-1179-3005 & $\begin{array}{l}\text { Conceptualization, Methodology, Investigation, Formal Analysis, Writing - Original Draft } \\
\text { Preparation and Writing - Review and Editing. }\end{array}$ \\
\hline NKS & https://orcid.org/0000-0002-2977-5817 & $\begin{array}{l}\text { Conceptualization, Methodology, Investigation, Formal Analysis, Writing - Original Draft } \\
\text { Preparation and Writing - Review and Editing. }\end{array}$ \\
\hline WMAA & https://orcid.org/0000-0003-2366-3918 & Investigation, Formal Analysis and Writing - Review and Editing. \\
\hline MKA & https://orcid.org/0000-0001-7131-1752 & $\begin{array}{l}\text { Conceptualization, Logistic support, Writing - Original Draft Preparation and Writing - Review } \\
\text { and Editing. }\end{array}$ \\
\hline
\end{tabular}

\section{Financial Support}

This study was funded by the Universiti Sains Malaysia Short Term Grant (304/ PPSG/61313193).

\section{Conflict of Interest}

The authors declare no conflicts of interest. 


\section{Acknowledgements}

The authors would like to thank to all respondents, dentists, outpatient dental clinic staffs and everyone who have contributed to the success of this study.

\section{Data Availability}

The data used to support the findings of this study can be made available upon request to the corresponding author.

\section{References}

[1] Ahmad I, Nawaz A, Khan S, Khan H, Rashid MA, Khan MH. Predictors of patient satisfaction. Gomal J Med Sci 2011; 9(2):183-8.

[2] Prakash B. Patient satisfaction. J Cutan Aesthet Surg 2010; 3(3):151-5. https://doi.org/10.4103/0974-2077.74491

[3] Murray BP, Wiese HJ. Satisfaction with care and the utilization of dental services at a neighborhood health center. J Public Health Dent 1975; 35(3):170-6. https://doi.org/10.1111/j.1752-7325.1975.tbo0708.x

[4] Madhulatha G, Manasa P, Jaya Krishna B, Harshavardhan T. Evaluation of contentedness of patients over the services provided by comprehensive oral health care system. Int J Curr Res 2017; 9(9):57674-7.

[5] Mahrous MS, Hifnawy T. Patient satisfaction from dental services provided by the College of Dentistry, Taibah University, Saudi Arabia. J Taibah Univ Med Sci 2012; 7(2):104-9. https://doi.org/10.1016/j.jtumed.2012.12.002

[6] Skaret E, Berg E, Raadal M, Kvale G. Factors related to satisfaction with dental care among 23-year olds in Norway. Community Dent Oral Epidemiol 2005; 33(2):150-7. https://doi.org/10.1111/j.1600-0528.2004.00208.x

[7] John J, Yatim FM, Mani SA. Measuring service quality of public dental health care facilities in Kelantan, Malaysia. Asia-Pac J Public Health 2011; 23(5):742-53. https://doi.org/10.1177/1010539509357341

[8] Sitzia J, Wood N. Patient satisfaction: a review of issues and concepts. Soc Sci Med 1997; 45(12):1829-43. https://doi.org/10.1016/S0277-9536(97)00128-7

[9] Ha JF, Longnecker N. Doctor-patient communication: a review. Ochsner J 2010;10(1):38-43.

[10] Abd Aziz A, Izyan Farhana Nordin N, Mohd Noor N, Bachok Na, Nor Ismalina Isa S. Psychometric properties of the 'Skala Kepuasan Interaksi Perubatan-11'to measure patient satisfaction with physician-patient interaction in Malaysia. Fam Pract 2013; 31(2):236-44. https://doi.org/10.1093/fampra/cmt062

[11] Norhayati MN, Masseni AA, Azlina I. Patient satisfaction with doctor-patient interaction and its association with modifiable cardiovascular risk factors among moderately-high risk patients in primary healthcare. PeerJ 2017; 5:e2983. https://doi.org/10.7717/peerj.2983

[12] Meakin R, Weinman J. The 'Medical interview satisfaction scale'(MISS-2 1) adapted for British general practice. Fam Pract 2002; 19(3):257-63. https://doi.org/10.1093/fampra/19.3.257

[13] Bedi R, Gulati N, McGrath C. A study of satisfaction with dental services among adults in the United Kingdom. Br Dent J 2005; 198(7):433-7. https://doi.org/10.1038/sj.bdj.4812198

[14] Othman N, Razak IA. Satisfaction with school dental service provided by mobile dental squads. Asia Pac J Public Health 2010; 22(4):415-25. https://doi.org/10.1177/1010539510370794

[15] Rohit D, Rafeek R. Patient satisfaction with dental care treatment at a health facility in Trinidad. Int J Dent Health Sci 2017; 4(2):267-78.

[16] Gürdal P, Çankaya H, Önem E, Dinçer S, Yílmaz T. Factors of patient satisfaction/dissatisfaction in a dental faculty outpatient clinic in Turkey. Community Dent Oral Epidemiol 2000; 28(6):461-9. https://doi.org/10.1034/j.1600-0528.2000.028006461.x

[17] Al-Hussyeen AJA. Factors affecting utilization of dental health services and satisfaction among adolescent females in Riyadh City. Saudi Dent J 2010; 22(1):19-25. https://doi.org/10.1016/j.sdentj.2009.12.004

[18] Rambhia M, Shah K, Bhate P, Kalra D, Rajeev H. Evaluation of Patient Satisfaction Based on Communication Skills of Dentists in Mumbai City: A Cross-Sectional Questionnaire Based Survey. Int J Sci Study 2016; 3(11):48-52. https://doi.org/10.17354/ijss/2016/55

[19] Al-Mobeeriek A. Dentist-patient communication as perceived by patients in Riyadh, Saudi Arabia. Int J Occup Med Environ Health 2012; 25(1):89-96. https://doi.org 10.2478/s13382-012-0001-2

[20] Henríquez-Tejo RB, Cartes-Velásquez RA. Patients' perceptions about dentists: a literature review. Odontoestomatologia 2016;18(27):15-22.

[21] Swami V, McClelland A, Bedi R, Furnham A. The influence of practitioner nationality, experience, and sex in shaping patient preferences for dentists. Int Dent J 2011; 61(4):193-8. https://doi.org/10.1111/j.1875-595X.2011.00056.x

[22] Furnham A, Swami V. Patient preferences for dentists. Psychol Health Med 2009; 14(2):143-9. https://doi.org/10.1080/13548500802282690

[23] Smith MK, Dundes L. The implications of gender stereotypes for the dentist-patient relationship. J Dent Educ 2008; 72(5):562-70. https://doi.org/10.1002/j.0022-0337.2008.72.5.tb04520.x

[24] Balhaddad AA, Alshammari A, AlqADi AH, Nazir MA. Patient Satisfaction with Dental Services and Associated Factors in a Saudi Dental Institution. J Clin Diagn Res 2018; 12(12):36-9. https://doi.org/10.7860/JCDR/2018/38358.12399 